Check for updates

London, UK

Cite this as: BMJ 2021;372:n245 http://dx.doi.org/10.1136/bmj.n245 Published: 01 February 2021

\section{Why we ... cook for each other}

\section{Deputy practice manager Chloe Lamont talks to Helen Jones about the group activities that have boosted her colleagues' morale during the pandemic}

\section{Helen Jones}

King Edward Road Surgery is a busy practice in Northampton with 30 permanent staff and five or so medical students, registrars, and foundation doctors.

When the pandemic began the practice set up a wellbeing team to boost morale and ensure that everyone felt supported, says deputy practice manager Chloe Lamont. "We recruited happy people, who we thought could spread happiness to others. They get together for 20 minutes a week and come up with ideas on how we can all help each other," she says.

Even before the crisis the team did things to boost each other's morale. "Being a GP can be stressful and the reception staff never get a minute to themselves-during covid-19 everything has been worse, so we do things to make people feel valued," she explains. "If people feel valued and are happier in the workplace, then they are more likely to exceed at their job."

For the past couple of years, the practice team has been cooking meals for each other as a way of getting together and boosting morale. "We are a very diverse group from a lot of different cultures," says Lamont. "One of our trainee registrars brought in some Nigerian food for us, and then everyone got involved."

Before the pandemic the team ate lunch together every Thursday and this has continued in a socially distanced way. The team would also normally get together for garden parties hosted at one of the doctor's homes and regularly go out for meals together.

During December, the practice runs an "angels" scheme, where each team member is assigned a colleague for whom they carry out anonymous acts of kindness. "You might get a note on your desk, some chocolate, or perhaps a coffee in the morning," says Lamont. "It's to let people know that they are cared about and appreciated."

The team also takes part in regular bingo sessions and quizzes with prizes such as chocolates or sometimes half a day off.

\section{The GP view}

GP partner Mahmood Kausar says that he and his partner colleagues are aware of how practice staff are feeling. "We work on the principle that each of us has an important part to play and as such we support each other through the good times and the difficult ones. Simple things like asking how someone is can be hugely beneficial. We do a lot of things to keep team spirits up."

Judith Reeder, senior GP partner and freedom to speak up guardian at the practice, says, "One of the most important things about any workplace is the people. I place huge value on the relationships and friendships I have at work."

She adds, "The work is challenging for all staff and the pressure is unrelenting. You can only work under these pressures if you have good support and social interactions. Humour is also vital, and having fun is more restorative than anything else."

\section{How to make the change}

- Consider creating a wellbeing team who can meet and share ideas

- If you want to set up regular moral boosting initiatives identify organised, creative people who can take the lead

- You don't have to organise anything very complicated-there are plenty of ready made quizzes on the internet, for example 